\title{
Reported characteristics of children referred from primary care to pediatric allergy specialist care
}

\author{
TM Brakel ${ }^{1 *}$, BMJ Flokstra-de Blok ${ }^{1}$, JNG Oude Elberink ${ }^{2}$, MLA Schuttelaar ${ }^{3}$, WA Christoffers ${ }^{3}$, EM Roerdink ${ }^{4}$, \\ T van der Molen ${ }^{1}$, AEJ Dubois ${ }^{4}$ \\ From Food Allergy and Anaphylaxis Meeting (FAAM 2013) \\ Nice, France. 7-9 February 2013
}

\section{Background}

For the majority of patients suspected of allergy, management is mostly the responsibility of general practitioners (GPs), but may include specialist referral in selected cases. The purpose of this study is to obtain insight in characteristics of children that are referred from primary care to pediatric specialist care for diagnosis and treatment.

\section{Methods}

Children referred September 2011 and October 2012 to a pediatric allergy clinic were sent a questionnaire which was completed at home. Parents of referred children reported about their child's allergy.

\section{Results}

Of the questionnaires that were sent out $62 \%$ was returned. From the children $\left(n=81, M_{\text {age }}=8\right.$ years; range 3 months to 17 years) $57 \%$ was male. For $17.3 \%$ of the children no diagnosis had been established, 1 allergy diagnose was reported in $25.9 \%$ of the referred children, and $56.7 \%$ reported to have a diagnose for multiple allergies. Of the children for whom one or more diagnoses were reported, $59.8 \%$ had eczema, $43.9 \%$ food allergy, $29.2 \%$ rhinitis, $23.2 \%$ asthma and $24.4 \%$ had another allergy, not specified. Reference to the specialist due to anaphylactic reactions was reported in $81.6 \%$ of the cases. The anaphylactic reactions were caused by food products (80.3\%), drugs $(9.1 \%)$, insect venoms $(6.1 \%)$, and unknown cause (4.5\%). Reported symptoms of anaphylaxis to foods, drugs, and insect venoms were: dizziness and/or palpitations $12.1 \%$, loss of consciousness $6.1 \%$, nausea and/or abdominal cramps $37.9 \%$, vomiting and/or

'Department of General Practice, University Medical Center Groningen, Groningen, the Netherlands

Full list of author information is available at the end of the article diarrhea $24.2 \%$, itching in the mouth, ears and/or throat $36.4 \%$, itching of the tongue and/or lips $19.7 \%$, itchy and/ or watery eyes $37.9 \%$, tongue and/ or lips swelling $28.8 \%$, tightness of the throat $37.9 \%$, and cough $28.8 \%$. It was reported what quantity of food caused complaints, in $64.3 \%$ it were crumbs to a few bites /sips, in $12.5 \%$ it was a daily portion, and $23.2 \%$ did not know. The most common allergenic foods suspected to cause the allergy in food induced anaphylaxis were peanuts $62.3 \%$, milk $34 \%$ $8 \%$, hazelnut $30.2 \%$, walnut $26.4 \%$, egg $24.5 \%$, cashew $24.5 \%$, pistachio $24.5 \%$, and almond $20.8 \%$.

\section{Conclusion}

Anaphylaxis was the most frequently suspected diagnosis leading to specialist referral and foods were the most frequent cause of anaphylaxis. This suggests that GP's seek specialist support most often for this category of patients. Our next step will be to evaluate the management plan developed by specialists for these 81 children.

\section{Disclosure of interest}

None declared.

\section{Author details}

${ }^{1}$ Department of General Practice, University Medical Center Groningen, Groningen, the Netherlands. ${ }^{2}$ Department of Allergology, University Medical Center Groningen, Groningen, the Netherlands. ${ }^{3}$ Department of

Dermatology, University Medical Center Groningen, Groningen, the Netherlands. ${ }^{4}$ Department of Pediatric Pulmonology and Pediatric Allergy, University Medical Center Groningen, Groningen, the Netherlands.

Published: 25 July 2013

\section{doi:10.1186/2045-7022-3-S3-P68}

Cite this article as: Brakel et al:: Reported characteristics of children referred from primary care to pediatric allergy specialist care. Clinical and Translational Allergy 2013 3(Suppl 3):P68.

\section{C)

